Die Dauer der Stromunterbrechnng im Näpfchen c kann man durch Aufwärtsschrauben desselben beliebig verkleinern und durch Abwärtsschrauben beliebig rergrössern und dadurch im Näpfchen $d$ von je 5 Funken, welche die Stimmgabel $S$ während einer Schwingung des Eisenstabes $T$ liefert, einen oder zwei oder mehrere oder selbst alle zum Verschwinden bringen. Wird das Näpfchen c dagegen so hoch geschraubt, dass in demselben keine Stromunterbrechung mebr stattfindet, so fällt selbstverständlich im Näpfchen d gar kein Fanke melar aus und man erbält in dernselhen eine continuirliche Funkenteibe.

Die in den Näpfchen $c$ und $d$ auftretenden Funken sind wegen der primären Spirale des Funkeninductors sehr stark und es kommt daher vorzüglich im Näpfchen d zu unangenehmer Verbrennung and Zerstäubung des Quecksilbers, wenn man nicht dafür sorgt, dass beständig stark verdûnnter Alkohol in dasselbe nachfliesst.

\title{
XXIX.
}

\section{Die Resorption von Blut in der vorderen Augenkammer.}

\author{
Von Dr. Max Knies, \\ erstem Assistenten am physiologischen Institute zu Heidelberg.
}

Die Arbeiten, die sich bis jetzt mit den Schicksalen der Blutungen in die vordere Augenkammer beschäftigten, haben dieselben vorwiegend nur vorm klinischen Standpunkt aus in's Auge gefasst. Es sind fast überall nur makroskopische Beobachtungen über die Veränderungen, die das in der vorderen Kammer befindlicbe Blut erleidet, soweit sie beim Lebenden bei einfacher oder seitlicher Beleuchtung wahrgenommen werden können.

Man weiss, dass die Mebraahl der Fâlle günstig verläuft, dass völlige Resorption die Regel ist, falls im Auge selbst keine krankbaften Veränderungen vorbanden sind. Man weiss, dass dieser günstige Ausgang oft ohne alle Kunsthülfe eintritl; hingegen sollen gewisse Mittel, besonders Eis, Atropin, Druckverband ete. die Resorption beschleunigen, ohne dass man hierfür eine geniugende Erhlärung anzageben wïsste. Ein wesentlicher Unterschied zeigte sich sodann, je nacbdem das Blut gerann, oder nicht; im ersteren Falle wurde natürlich die Resorption selr verzögert oder kam uberhaupt gar nicht völlig zu Stande, sondern nur mit Hinterlassung von Gerinnseln oder Pigment, was je nach der zufälligeu Lage mehr oder 
weniger Störungen veranlasste. Ganz anders ist der Verlauf bei pathologischen, besonders chronisch-entzündlichen Zuständen im Augapfel. Hier finden wir angegeben, dass selbst nach Jahresfrist noch flüssiges Blut die vordere Kammer erfülte, obschon freilich der mikroskopische Beweis fehlt, dass die rothe Flüssigkeit, die im Auge zu seher war, auch wirklich unverändertes Blut gewesen ist. Jedenfalls wird unter solchen Verhältnissen die Resorption des Blutes, wenn sie überbaupt zu Stande kommt, ganz ausserordentlich verzögert. Es ist nun begreiflicherweise von Interesse, den Weg genau zu kennen, auf dem die Aufsaugung vor sich geht. Diesen möglichst zu ermitteln war, neben der Erforschung der Veränderungen der Formbestandtheile des Blutes, der Zweck der vorliegenden Arbeit. Naturgemäss müssen im Grossen und Ganzen die Resorptionswege dieselben sein, in denen auch unter normalen Verhältnissen der Stoffwechsel vor sich gebt, und die Arbeit, die rorwiegend pathologiscber Natur ist, gewinnt dadurch auch ein plysiologisches Interesse.

Es liegen bereits verschiedene Árbeiten vor, die sich speciell mit dem Stoffwechsel im Auge befassen. Welche Stoffe und in welcher Zeil sie im Auge nachgewiesen werden können, nachdem sie vorher in den Vèrdauungskanal, in's Unterhautbindegewebe, in die Blutbahn direct oder in den Conjunctivalsack gebracht worden waren, hat M. Mimocky untersucht (Graefe's Archiv XI. 2. S.84 bes. S. $112 \mathrm{ff}$.). Vergl. auch Kisielow: Zur Frage über die Durchdringbarkeit von Flüssigkeit durch die Hornhaut eines lebenden Menschen. Petersburg 1869. Während Mimocky in den Conjunctivalsack gebrachtes Blutlaugensalz am lebenden Hund nie in der vorderen Kammer nachweisen konnte, behauptet Kisielow, Atropin und Jodkalium unter denselben Verhältnissen nachgewiesen zu haben. Leber (Studien über den Flüssigkeitswechsel im auge, Graefe's Archiv XIX. 2. $87 \mathrm{ff}$.) hat die Druckverhälnisse im Auge und deren Ausgleich hauptsächlich bei abnorm hohem Druck behandelt. Auch suchte derselbe durch Injection von Farbstoffen diffundirender und nicht diffundirender Natur (Carmin und lösliches Berliner Blau) die Resorptionswege direct zu zeigen. Die Versuche wurden mit concentrirten Lösungen und unter abuorm hohem, den normalen um das Doppelte und Dreifache übersteigenden Druck vorgenommen, und sind deshalb, abgesehen von ihrem negativen Er- 
folge bei gewöhnlichem Druck, hier nicht gut zu verwerthen. Leber kam zu dem Resultat, dass die Resorption hauptsächlich an der Stelle des Ligamentum pectinatum vor sich gehe, und dass im Uebrigen die Wände der vorderen Kammer fast unbetheiligt seien. Die Weiterführung der eingebrachten Stoffe geschehe durch die Blutgefässe, doch communicire die vordere Kammer, entgegen der Schwalbe'schen Ansicht, direct weder mit Blut- noch mit Lymphgefässen. Auf diese zuletzl erwähnten vielbestrittenen histologischen Details wird diese Arbeit nicht weiter eingehen; es lag vielmehr nur in meiner Absicht, festzustellen, wo, wie und wodurch die in der vorderen Kammer befindlichen Blutbestandtheile nach aussen weiter geschafft werden. Es ist einigermaassen sonderbar, dass von den dreierlei fremden Elementen, die, abgesehen von den eigentlichen Fremdkörpern, in der vorderen Kammer angetroffen werden: Eiter, Linsensubstanz und Blut, gerade letzteres so wenig genau untersucht ist. Ueber die Resorption von Linsensubstanz ist rorzugsweise eine Arbeit von C. Ritter mir bekannt (Graefe's Archiv VIII. 1. 1 ff. bes. S. 27 ff.); über den Eiter in der vorderen Kammer existirt eine ganze Menge von Mittheilungen; man denke nur an die Literatur über drs Hypopyon. Dieselben beschäftigen sich aber vorwiegend mit dem Woher? und nicht mit dem Wohin?

Als hauptsächlich benutzte Arbeiten möchte ích hier ein für allemal erwähnen: Donders, Imbibitionserscheinungen aer Cornea. Graef. Arch. III. 1. S, 166 If, C. Ritter, Graef. Arch. VIII. 1. S. 1 fi. bes. $27 \mathrm{ff}$.

Mítrophan Mimocky, Einfluss des intraoculären Druckes auf die Blutbewegung im Auge und experimentelle Beiträge zur Diffusion im Auge. G. A. XI, 2 . S. $84 \mathrm{lf}$.

Leber, Imprägnationsmethaden der Cornea u. s. w. Graef. Arch. XIV. 3. $300 \mathrm{ff}$. Leber, Studien über den Flüssigkeitswechsel im Auge. Graef. Arch. XIX. 2. S.87. Danthon, Essai sur les hémorrhagies intraoculaires. Paris 1864.

Das Schicksal des Blutes sollte unter möglichst normalen, respective unter möglichst wenig abnormen Verhältnissen in der vorderen Kammer untersucht werden, und demgemäss waren die Versuche so einzurichten, dass die eingebrachte möglichst indifferente Flïssigkeit an Stelle des Kammerwassers die einzige Abweichung von den normalen Verhältnissen war. Da das Blut eine sebr complicirte Zusammensetzung hat, und man die Veränderungen seiner Bestandtheile nur theilweise, die Wege auf denen es resorbirt wird, gar njebt direct sehen kann, so musste nach Surrogaten für die 
einzelnen Kategorien von Blutbestandtheilen gesucht werden, die tauglicher zur Beobachtung wären. Ganz von selbst ergiebt es sich, dass man gelöste und ungelöste Stoffe zu unterscheider hat; bei ersteren sind die Bedingungen verschieden, je nachdem sie diffundiren oder nicht, bei letzteren, je nachdem sie löslich sind oder njcht. Danach ist die naturyemässé Eintheilung:

1) Das Verhalten diffundirender Stoffe.

2) Das Verbalten nicht diffundirender Stoffe.

3) Das Verhalten der geformten Bestandtheile des Blutes.

Da die unter die beiden ersten Kategorien fallenden Blutbestandtheile als solche nicht nachzuweisen sind, so mussten sie durch andere ersetzt werden, die 1) möglichst indifferenter Natur und 2) auch in minimalen Quantitäten leicht und sicher nachzuweisen sind. Als solche wurden gelbes Blutlaugensalz und lösliche Stärke aus leicht begreiflichen Gründen gewählt. Die Untersuchung der Blutkörperchen und des etwa ausgeschiedenen Fibrius konnte direct mit dem Mikroskop vorgenommen werden.

1.

Injectionen von gelbem Blutlaugensalz.

Als Material wurde eine Lösung genommen, die ungefähr 12 pCt. krystallisirtes Salz enthielt. Da bei wiederholten Versuchen die Canülen der benutzten Pravaz'schen Spritze nach der Injection wieder zu entfernen, fast immer die injicirte Flüssigkejt durch den Stichkanal wieder abfloss, so entschloss ich mich, wenn auch ungerm, die Canülen liegen zu lassen, wie es auch Leber bei seinen Druckversuchen gethan hat. Es zeigten sich aber in keinem Falle irgend welche Entzündungserscheinungen, was leicht begreiflich ist, da Berührung der Iris sorgfältigst vermieden wurde, und die Canüle nur zwischen $\frac{1}{2}$ und 3 Stunden liegen blieb, nach welcher Zeit die benutzten Kaninchen getödtet wurden. Eine sehr genaue Fixation des Auges ist dringend nothwendig, da besonders im Momente des Eintretens der Flüssigkeit sehr ausgiebige Reflexbewegungen zu erfolgen pflegen. Der Kopf des Kaninchens wurde in einem Kopfhalter unbeweglich befestigt, die Lider durch einen Assistenten geöffnet erhalten, und der Bulbus selbst noch dureh einen Faden, der unter dem Rectus superior durchgeführt warde, an Bewegungen gehindert. Trotz aller dieser Vorsichtsmaassregeln sind docb ein- 
zelne Versuche misslungen. Die Injection geschah dann aut die Art, dass die Canüle einer. Prava z'schen Spritze mit recht langer Spitze vor der vorderen Oeffnung unter Zuhalten der hinteren Oeffnung durch die Cornea hindurch und auf der anderen Seite mit der Spitze bis in dieselbe hineingeführt wurde, um für den folgenden Act das Auge recht sicher zu fixiren. Verletzung der Iris wurde dabei immer sorgfälligst vermieden und im Falle, dass sie doch eintrat, der Versuch verworfen. Dann wurde die äussere Oeffnung der Canüle freigegeben und das Kammerwasser abfliessen gelassen. Hierauf wurde soviel injicirt, bis ich glaubte, eine normale Füllung der vorderen Kammer herbeigefübrt zu haben und bis die vordere Irisfläche die Canüle nicht mehr beriuhrte; sodann wurde die Canüle vollends durch die Cornea durchgestossen, so dass ihre Oeffnung ausserbalb der Kammer lag und dieselbe liegen gelassen. Das Kaninchen blieb natürlich aufgebunden liegen. Im Ganzen war es für den Erfolg ziemlich gleichgültig, ob man $\frac{1}{2}$ oder 3 Stunden wartete; nur war in einem Falle nach 3 Stunden keine Spur von Ferrocyankalium im Auge mehr nachzuweisen. Das Resultat war in allen Fällen qualitativ völlig gleich und nur quantilativ verschieden. Um eine Resorption vom Conjunctivalsack aus auszuschliessen, obschon dieselben nach den Versuchen von Mimocky (l. c.) nicht zu erwarten war, wurde derselbe nach vollendeter Operation sofort auf das Sorgfältigste ausgespült. Nach Ablauf der bestimmten Zeit wurde das Versuchsthier gewöhnlich durch Enthauptung, zuweilen auch durch Verblutung getödtet and zuerst das vorbandene Kammerwasser untersucht. Es ergab sich immer, mit Ausnahme eines schon erwähnten Falles, der nach 3 Stunden zur Untersuchung kam, durch Eisenchlorid deutlich, dass noch Ferrocyankalium vorhanden war: es entstand ein amorpher Niederschlag, der offenbar aus Weiss und Blau zusammengesetzt war. Die Cornea wurde nun entweder abgelöst und besonders untersucht, nachdem sie äusserlich, ebenso, wie die Wände der vorderen Kammer überhaupt gut abgespült war, oder das ganze Auge wurde sofort von vorn nach hinten halbirt und in eine Mischung gebracht, die aus gleichen Theilen einer concentrirten Kochsalzlösung und einer dunkelgelben Lösung von Eisenchlorid zusammengesetzt war, worin sich das Auge sehr gut hielt und zugleich bis zum folgenden Tage genügend gehärtet wurde. 
Unter diesen Verhältnissen untersucht, zejgte die ganze Cornea eine deulliche Blaufärbung. Besonders intensiv, aber scharf begrenzt und nur auf die nächste Umgebung beschränkt waren die Stichkanäle gefärbt; ebenso die der vorderen Kammer zunächstliegenden Hornhautlamellen. Bei der mikroskopischen Untersuchung stellt sich der Epithelbelag der Membrana Descemeti wie nach Silberfärbung, aber in blauen Contouren dar (vergl. Leber, Imprägnationsmethoden der Cornea, Graefe's Archiv XIV. 3. S.300 ff.). An einzelnen Stellen zeigen sich Lücken zwischen den Endothelzellen, die offenbar identisch mit den Recklinghausen'schen Stomata sind und jedenfalls nicht wie eine ausgefallene Zelle aussehen. Die elastische Descem et'sche Membran zeigt schwächere, diffuse Blaufärbung; am intensivsten aber ist die Hornhautsubstanz selbst gefärbt, je nach der Menge des eingespritzten Salzes oder der Dauer der Einwirkung mehr oder weniger weit nach aussen. Gewöhnlich waren die 3-6 innersten Hornbautlamellen, wenn ich mich so ausdrücken darf, stark blau gefärbt mit von innen nach aussen abnehmender Intensitäl. Flächenansichten zeigten die bekannten negativen Bilder der Hornhautkörperchen in ausgezeichnet schöner Weise; bei gut gelungenen Schnitten, die die Lamellen schief trafen, konnte man 3,4 und̉ mehr Schichten weisser Hornhautkörperchen in blauer Grundsubstanz, deren Fürbung von innen nach aussen abnahm, je nach der Einstellung des Mikroskops nach einander zur Anschanung bringen. An Zerzupfungspräparaten konnte man leicht die Grundsubstanz in diffus blaugefärbte Fasern zerspalten. Der übrige Theil der Hornhaut war gleichmässig schwach blau gefärbt und zeigte nach aussen keine weitere Abnahme der Intensität. Bei Flächenansichten auf die vordere Corneafläche sah man zuweilen die Kiltlejsten zwischen den Epitheizellen gleichfalls schwach, aber deutlich blau gefärbt, während die Zellen selbst ganz ungefärbt blieben. Um den Stichkanal herum zeigten sich zwei scharfe Contouren; die nächste Nähe ist intensiv blau gefärbt; dann folgt eine etwas grössere weniger blaue Zone, welche mit scharfem, etwas dunklerem Rande gegen die ibrige Hornhautsubstanz abschliesst, die sich sodann in der Färbung von anderen Steljen nicht weiter unterscheidet. Zuweilen ist an der inneren Stjchöffnung die elastische Membrana Descemeti von der Hornhaut etwas abgelöst und in dieser immer nur sehr unbedeutenden Lücke zeigt sich der blaue Nieder- 
schlag wie im Kammerwasser aus Körnchen bestebend. Die Conjunctiva selerae ist schwach bläulich; intensiver gefärbt ist das subconjunctivale Gewebe und lässt dasselbe auf der Flächenansicht zuweilen ganz dasselbe Bild, wie die der Kammer zunächst liegenden Hornhautschichten sehen, nehmlich weisse zackige Bindegewebskörperchen in dunkelblaner Zwischensubstanz. Im Uebrigen zeigten die Wände der vorderen Kammer nichts Besonderes. Eine Blaufärbung der Regenbogenhaut konnte jch nicht wahrnehmen, ausser in der Nähe ihrer Insertionsstelle; überhaupt war die Gegend des Ligamenium pectinatum stärker blau gefärbt. Auch die vordere Linsenkapsel zeigte einmal eine schwache Bläuung, die aber nur an Stellen zu erkennen war, an denen sie mehrfach übereinander lag. Weiter nach hinten im Auge konnte ich nie eine Blaufärbung nachweisen. $\mathrm{Zu}$ hemerken ist noch, dass immer an einzelnen Stellen Zellen im Endothelbelay der Membrana Descemeti ausgefallen waren. Dem entsprechend zeigte sich auf der Fläche eine stärkere, scharf contourirte Blaufärbung, deren Umfang etwas grösser war, als der der ausgefallenen Zellen. Mit den weiter oben als Recklinghausen'sche Stomata bezeichneten stärker blaugefärbten Stellen waren sie nicht zu verwechseln; letztere waren viel kleiner und die blaue Färbung entsprach genau dem Zwischenraum zwisehen den einzelnen Zellen. An anderen Stellen wechselten auf der Flăchenansicht dunkler und heller gefärbte Stelleu in der Hornhautsubstanz unregelmässig und ohne scharfe Contouren mit einander ab. Ueber beiderlei Stellen setzte sjch aber der Endothelzellenbelag gleichmässig fort, so dass ein Zusammenhang zwischen Fehlen des Endothels und stärkerer Blaufärbung hier nicht zu erweisen war. Um dem Einwurfe zu begegnen, dass die ziemlich starke Salzlösung eine Veränderung in den Geweben des Auges, speciell im Endothelbelag der Membrana Descemeti hervorgebracbt babe, wurden Controlversuche gemacht, wobei dieselbe Blutlaugensalzlösung injicirt und das Thier am Leben gelassen wurde. Nach den Beobachtungen von Leber (1. c.) müssten, falls das hintere Epithel der Cornea abgestorben wäre oder sich losgelöst hätte, an den betreffenden Stellen Trühungen der Hornhaut eintreten. Ausser einer leichten Trübung an den Einstichpunkten, die aber nach 2-3 Tagen vollständig wieder versehwunden war, war jedoch absolut Nichts wahrzunehmen, die Thiere nach Ablauf dieser Zeit zu 
tödten und die Augen noch nachträglich zu untersuchen, hielt ich für völlig unnöthig, da doch nur ein negatives Resultat zu erwarten was. Genügten ja doch in einem Falle 3 Stunden, um das injicirte Blutlaugensalz spurlos aus dem Auge fortzuschaffen.

II.

Injectionen von löslicher Stärke.

Die Injectionen wurden mit einer filtrirten Lösung einer reinen löslichen Stärke, die mir durch die Güte des Herrn Prof. Kühne zur Verfügung gestellt war, und unter denselben Vorsichtsmaassregelu, wie die mit gelbem Blutlaugensalz vorgenommen. Zu bemerken ist noch, dass die Stärkelösung vollständig neutral reagirte, nicht sauer, wie es wegen der zur Darstellung der löslichen Stärke angewendeten Weinsäure leicht hätte der Fall sein können. Die Flüssigkeit wurde ungefähr 3 Stunden lang in der vorderen Kammer gelassen, ehe das Thier auf dieselbe Weise, wie bei den früheren Versuchen getödtet wurde. Die Untersuchung und Eröffnung des Auges geschah gleichfalls auf dieselbe Weise, wie bei den Versuchen mit Blutlaugensalz. Von den Canülen liess sich eine braune Flüssigkeit abwischen und ebenso waren die Stichkanäle braun gefärbt. Diese Flïssigkeit reagirte neutral oder schwach sauer, während die Reaction des Kammerwassers und der sonstigen Augengewebe stark alkalisch war. Das Eisen der Canälen sah, soweit dieselben in der vorderen Kammer lagen, matt und wie angeätzt aus. Auf der vorderen Irisfläche lag lose eine graue, dünne, nicht sehr zerreissliche Membran, die unter dem Mikroskop feinkörnig erschien und mit grösster Wahrscheinlichkeit als fibrinöser Niederschlag zu deuten war. Zellige Elemente konnte ich in ihr nicht entdecken; dagegen zeigte sie auf Jodzusatz schwach aber deutlich eine violette Färbung. Sonst war aber im ganzen Auge auf Jodzusatz nirgends eine Spur von blauer oder violetter Färbung $z u$ sehen. Dagegen gab Cornea und Kammerwasser bei Behandlung mit Kalihydrat und Kupfervitriol eine sehr deutliche Reduction zu Kupferoxydul, was weder die ursprüngliche Stärkelösung, noch eine Cornea eines frischen Auges, noch frisches Kammerwasser für sich aufgefangen, that. Unzweifeltuaft war also eine Umwandlung der Stärke vor sich gegangen. Da ich nicht annehmen kann, dass eine Stärkelösung, wie jeh sie anwandte, die noch nicht 2 pCt. Stärke enthielt, ștärker reizt, als die früher ge- 
brauchte Lösung von gelbem Blutlaugensalz, so glaube ich, dass die Reizerscheinung der fibrinösen Exsudatmembran, die bei Injection von Ferrocyankalium nie auftrat, auf Rechnung der primären und secundären Zersetzungsproducte der Stärse zu setzen ist. Controlversuche zu machen, oh Injection von Stärkelösung auf die Dauer einen schädlichen Einfluss habe, fand ich nicht nöthig, da dieselbe zersetzt wird, und wir die Zersetzungsproducte nur vermuthen können, allerdings mit grosser Wahrscheinlichkeit. Ich dehnte auch die Versuche mit sogenannten Colloidsubstanzen nicht auf andere Stoffe aus, da mir sonst keiner bekannt ist, der milkrochemische Reactionell in den hier vorkommenden Verdünnungen mit der nöthigen Schärfe zu geben vermag, ohne voraussichtlich, wie Dextrin und Glycogen, dieselben Veränderungen beim Aufenthalt in der vorderen Kammer zu erleiden. Da nun in der vorderen Kammer, wenigstens in der fibrinösen Membran mit Jod noch Blaufärbung eintrat, also noch Stärke vorhanden war, sonst aber nirgends im Auge, weder in der Hornhaut, noch in der Iris, noch in der Gegend des Ligamentum pectinatum und im subconjunctivalen Gewebe, so glaube ich, dass sämmtliche Stärke erst als diffusionsfähiges Umwandlungsproduct aufgenommen wird. Wenn man Stärkelösung in die Hornhaut selbst einspritzt und bald darauf untersucht, so kann man mit Leichtigkeit eine Blaufärbung nachweisen, soweit die Flüssigkeit gedrungen ist. Es erscheint die Grundsubstanz tief blau gefärbt, und man erkennt darin die noch dunkler gefärbten Hornhautkörperchen. Letztere scheinen demnach, während sie den Krystalloidsubstanzen gegenüber sich im Leben passiv verhalten, im Gegentheil den Colloidsubstanzen gegenüber eine gewisse Anziehungskraft auszuaiben. $O b$ aber in ihnen die Umwandlung in diffusionsfähige Körper geschehe, wage ich nicht zu behaupten; dies müssen weitere Versuche lehren. Jedenfalls ist die Grundsubstanz fähig init Lösung eines Colloidstoffes sich zu tränken, wie ihre starke Blaufärbung mit Jod beweist. Auch zeigt letzteres, dass die Hornhautsubstanz und die sie durchtränkende Flüssigkeit kein Hinderniss für die Jodreaction abgiebt, was in unserem Falle nicht ohne Wichtigkeit ist, als durch das Ausbleiben der Reaction mit Sicherheit auf das Nichtvorhandensein von Stärke im Gewebe der Cornea und der anderen Wände der vorderen Kammer geschlossen werden kann. Als Umwandlungsproduct der Stärke ist wohl zuerst an 
Traubenzucker zu denken, und in der That gab die an Kammerwasser und Hornhaut angestellte Trommer'sche Probe einen positiven Anhaltspunkt. Da nun das Kammerwasser normaler Weise kein zuckerbildendes Ferment enthält, so muss man wohl annehmen, dass dasselbe erst nach der Injection aufgetreten sei. Ich selbst lounte wenigstens, nachdem ich von derselben Stärkelösung einige Cubikcentimeter mit frisch abgelassenem Kammerwasser eine Nacht lang bei $35^{\circ} \mathrm{G}$. im Brütofen liess, den anderen Morgen keine Spur einer Reduction von Kupferoxyd bemerken; wohl aber gab die betreffende Lösung wit Jod intensive Stärkereaction. Immerhin wäre aber, wie schon oben gesagt, auch noch an eine specielle Zellenthåtigkeit im Sinne der Umwandlung von Stärke zn denken; doch lassen sich hierüber nur Vermuthungen ausstellev. Auf die Umwandlung der Stärke zu Zucker beschränkt sich aber der Unwandlungsprozess augenseheinlich nicht. Wie nachgewiesen ist,. dass auch vom Darmkanal aus ein beträchtlicher Theil des Zuckers erst als Milchsäure aufgenommen wird, so scheint auch in der vorderen Kammer derselbe Vorgang stattzufinden. Ob die gebildete Säure gerade Milchsäure ist, wird kaum nachzuweisen sein, ist aber auch von ganz untergeordnetem Interesse, da physiologisch Buttersäure oder gar Schleimsăure wohl denselben Effect haben würden. Dic hierbei allenfalls auftretenden Gase wirden dann unmittelbar nach der Entstebung resorbirt werden. Milchsäure scheint mir nach Analogie anderer Vorgänge im thierischen Körper immerhin am wahrscheinlichsten zu sein. Die alkalische Reaction des Kammerwassers beweist übrigens, dass die gebildete Säure, sowie sie die Absonderungsstellen des Kammerwassers berührt, sehr rasch durch Absonderung eines stark alkalischen Secretes neutralisirt wird. So schnell geschieht dies jedoch nicht, dass nicht vorher die Säure das Eisen der Canülen hätte angreifen können. Auch ist der Reizzustand der Iris, der sich durch Bildung einer fibrinösen Auflagerung documentirte, eher auf Recbnung einer freien Säure, als auf die einer schwachen Stärke- oder Zuckerlösung zu schreiben.

III.

Die bis jetzt mitgetheilten Thatsachen erklären sich nun, mit Ausschluss der Fermentwirkungen, auf folgende Weise sehr leicht.

Bekanntlich werden die hintere Kammer und besonders die Ciliar- 
fortsätze jetzt allgemein als Absonderungsstellen des Humor aqueus angenommen. $O b$ auch nebenbei die vordere Irisfläche secernire, ist zweifelhaft, mir persönlich indess nicht unwahrscheinlich. Die Erscheinungen bei Pupillarverschluss sprechen nicht absolut dagegen, da eben das von der vorderen Irisfläche abgesonderte Secret auf dem gewohnten Wege abfliessen kann. Auch die Thatsache, dass Leber bei Injectionen von Carmin die Iris geröthet fand, spricht nicht dagegen, da derselbe mit erhöhtem Druck (87 und $115 \mathrm{Mm}$. Quecksilber) untersuchte, in meinen Fällen dagegen bei möglichst normalem Druck die Iris nicht gefärbt gefunden wurde, abgesehen von der Insertionsstelle am Ligamentum pectinatum. Mag nun die vordere Irisfläche absondern, oder nicht, jedenfalls wird in der hinteren Augenkammer und durch die Giliarfortsätze vorwiegend secernirt. Die abgesonderte Flüssigkeit, der Humor aqueus, wird nun hauptsächlich in der Gegend des Ligamentum pectinatum resorbirt; aber auch die der vorderen Kammer zunächst liegenden Hornhautschichten betheiligen sich dabei, und die Salze diffundiren in minimaler Menge bis zum vorderen Epithel, da wie die Blaufärbung mit Eisenchlorid zejgte, die ganze Cornea vom Blutlaugensalz durchdrungen war. Diese Diffusion und Resorption findet wesentlich durch die Kittleisten, zwischen den einzelnen Endothelzellen und durch die Hornhautsubstanz statt, die beide genetisch als Intercellularsubstanz dasselbe sind. Die Zellen selbst verhalten sich völljg passiv dabei und scheinen besonders dadurch zu wirken, dass sie eben nicht mehr Salz durchtreten lassen, als ohne die Ernährung der Cornea zu beeinträchtigen auf den normalen Abflusswegen wieder weitergeschafft werden kann. Jede folgende Zellenschicht der Cornea verhält sich ähnlich, wie das Endothel der Descemet'schen Membran und wirkt gewissermaassen wie ein Filter, nur viel weniger vollkommen, da die Zellenlagen nicht so geschlossen sind, und die Intercellularsubstanz, in der die Diffusion stattindet, viel massiger ist. So erklären sich leicht die von innen nach aussen successsive schwächer werdenden negativen Bilder der Hornhautkörperchen. In der Hornhaut besteht nun eine Strömung vom Centrum nach der Peripherie und nach dem subconjunctivalen Gewebe, von wo aus die Stoffe in Venen oder Lymphgefässe gelangen und fortgeschafft werden. Dieselbe Flüssigkeitsströmung findet, wie allgemein angenommen, auch in der vorderen Kammer 
statt und am Ligamentum pectinatum wird direct aus dem Kammerwasser resorbirt. Dass für normale Verbältnisse blos der letztere Kreislauf bestebt, die Cornea etwa nur in Ausnabmefällen und zur Aushülfe eintrete, lässt sich als Möglichkeit allerdings nicht zurückweisen, ist aber nach Allem sehr wenig wahrscheinlich. Vergleicht man ausserdem noch, wozu man genetisch völlig berechtigt ist, die vordere Kammer mit jenen Spalträumen in der Cornea, wie sie durch gewisse Reagentien hervorgebracht werden; und wo jeweils die Zellen der einen Wand anliegen, so sieht man ganz und gar nicht ein, warum man eine Betheiligung der Hornhaut an der Resorption ausschliessen soll. Durch Flüssigkeitsansammlung z,wischen der letzten und vorletzten Hornhautlamelle, wenn ich mich so ausdrücken darf, entstebt die vordere Kammer; die Zellenschicht bleibt an der äusseren Lamelle bängen und wird durch das Hereinwachsen der Iris noch einmal eingestülpt. Die vorletzte Hornhautlamelle wandelt sjch zur elastischen Membrana Descemeti um, die letzte wird zur vorderen Linsenkapsel und diese würde sich ebenso gut blau färben, wie jene, wenn nicht der Flüssigkeitsstrom aus der binteren in die vordere Kammer den Diffusionsvorgängen nach hinten hinderlich wäre. Der Endothelüberzug dient nicht als absolutes Finderniss für den Durchtritt von Flüssigkeit, sondern nur als Regulator, und wie volkommen regulirt wird, zeigen die Leber'schen Druckversuche. Die Zeichnungen im subconjunctivalen Gewebe, die ich bei Injection von Blutlaugensalz zuweilen bekam und die man recht gut als negative Bilder der feinsten Lymphgefässe und Saftkanälchen bezeichnen kann, sprechen gerade nicht für directe Communication und liessen eher daran denken, dass auch hier die Resorption vorwiegend durch die Intercellularsubstanz geschehe. Doch ich habe hierüber zu wenig Erfahrung, um näher darauf einzugeben, und muss mich mit dem Gesagten begnügen.

Was der amorphe weisse Niederschlag war, der neben dem blauen ron Ferrocyaneisen bei Zusatz von Eisenchlorid zum Kammerwasser entstand, wage ich nicht bestimmt zu behaupten. Normales Kammerwasser giebt mit dem genannten Reagenz keine Fällung. Am wahrscheinlichsten wird es wohl ein Eiweisskörper sein, und es ist ja bekannt, dass dergleichen nach verhältnissmässig geringen Reizungen im Kammerwạsser reichlich aufưutreten pflegen, 
IV.

Bei Injectionen von Blut wàr es nie nöthig, die Canüle liegen zu lassen, da das nicht defibrinirte Blut bald gerann und auch defibrinirtes nicht leicht beim Anszieben der Canüle nachfloss. Andere pathologische Erscheinungen, als eine leichte Trübung an der Einstichsstelle in die Hornhaut wurden nicht bemerkt. Auch die Injectionen von Blut wurden sämmtlich an Kaninchen vorgenommen.

Injectionen mit defibrinirtem Blut zeigen makroskopisch nichts Besonderes; dagegen ist der mikroskopische Befund sehr interessant. Vom zweiten Tage an sind die weissen Blutkörperchen fast völlig verschwunden; die rothen zeigen neben vereinzelten völlig unveränderteu Formen, die man bis zum letzten Augenblick wahrnehmen kann, eine Reihe von Gestalten, die man sehr geneigt wäre, als Uebergänge von weissen zu rothen Blutkörperchen zu deuten, wenn dieselben im Verbältniss zu den im Blut vorhandenen weissen Blutkörperchen nicht allza zahlreich wären. Es macht den Eindruck, als ob weisse Blutkörperchen erst sich gelb färbten, dann eine glatte Oberfläche bekämen, dann den oder die Kerne verlören, danı zu dunkler gefärbten, etwas kleineren Kugeln würden, dann sich abplatteten und schliesslich mit der Delle vollkommene Grösse und Aussehen von normalen rothen Blutkörperchen annähmen. Die einzeInen Formen genau zu beschreiben, ist unmöglich, da hierbei die grösste Mannichfaltigkeit herrscht. Daneben sieht man offenbar sich auflösende rothe Blutkörperchen mit Fortsätzen, die sich abschnüren und zu kleinen rothen Kügelchen zerfallen, die in allen Grössen sehr zahlreich. vertreten sind. Vom zweiten oder dritten Tage an ist auch das Serum merklich gefärbt von aufgelöstem Blutfarbstoff. Bemerkenswerth ist, dass man auch noch nach 5 und 6 Tagen, allerdings aber nur sehr vereinzelt, völlig normal ausschende weisse Blutkörperchen findet. Man siebt genau dieselben Formen, wenn man defibrinirtes Blut in einem zugedecklen Ubrschälchen bei gewöhnlicher Temperatur (es war Hochsommer) der längeren Einwirkung von $\frac{1}{2}$ procentiger Kochsalzlösung oder der von Kammerwasser aussetzt. Auch hier verschwanden nach 24 Stunden die weissen Blutkörperchen, die vorher in normaler Zabl vorbanden waren, fast vollständig, ohne indess selbst nach 96 Stunden völlig vermisst zu werden. Es scheint nur, dass diese, Uebergangsformen ähnlichen, 
Gebilde ausserhalb des Körpers bei gewöhnlicher Temperatur in Kocbsalzlösung und Kammerwasser etwas langsamer auftreten. Auch beobachtete ich sie in Kammerwasser viel besser, als in einfacher Kochsalzlösung. Als Beispiel möchte ich folgenden Parallelversuch anfiihren: Ein paar Tropfen ganz frisches, defibrinirtes Hundeblut, das nach der Untersuchung völlig normales Verhalten zeigte und auch weisse Blutkörperchen ungefähr im normalen Verhältniss zu den rothen aufwies, wurden in je ein Schälehen mit Kammerwasser von demselben Thier und mit $\frac{1}{2}$ procentiger Kochsalzlösung gebracht. Nach je 24 Stunden wurden Proben genommen und mit dem Mikroskop untersucht.

Kammerwasser.

$\mathrm{NaCl} \frac{1}{2} \mathrm{pCt}$.

Nach 24 Stunden:

Die rothen Blutkörperchen sind kleiner geworden, meist zackig; daneben findet man grössere, mebr oder weniger unregelmässig geformte, blassere Körper mit und ohne Kerne im Verhältniss etwa $1: 3-4$ zu den rotuen; Flüssigkeit nicht merkbar gefärbt. Weisse Blutkörperchen stark vermindert.

Nach 48

Flüssigkeit gelb gefärbt. Man findet grosse, runde und biconcave, schwach höckrige, blassgelbe Körper, of mit 1-3 Kernen, aber auch obne solche. Daneben um $\frac{1}{2}-\frac{2}{3}$ kleinere runde und biconcave Körperchen, oft in Abschnürung begriffen. Am zahlreichsten kleine, stark zackige, dunklere Körperchen und scharf contolzrirte, grössere und kleinere Tröpfçben von gelber Farbe. Rothe Blutkörperchen von gewöbnlicher Form kein einziges zu finden. Weisse Blutkörperchen fast völlig verschwunden.

Nach 72 Stuaden:

Im Ganzen derselbe Befund.

Nach 96

Keine so aufiallenden Grössenunterschiede mehr; auch sind alle körperchen ziemlich gleichmässig gefärbt. Biconcave
Die rothen Blutkörperchen sind etwas mehr rundlich, viele sternförmig, aber nicht sebr ausgeprägt. Daneben grössere, granulirte, gelblich gefärbte, sternförmige Körper mit 1 und 2 Kernen. Flüssigkeit ungefärbt. Weisse Blutkörperchen sehr stark vermindert.

\section{Stunden:}

Im Wesentlichen derselbe Befund, wie den Tag vorber. Flüssigkeit mässig gelb gefärbt.
Standen:

Gar keine in die Augen fallenden Grössenunterschiede mehr. Viele Körperchen sind glatt, nur wenige stark gezähnt. 
Kammerwasser.

Körperchen sind ziemlich häufig; kein gefärbtes Körperchen enthält melhr einen Kern. Ganz vereinzelt noch völlig unveränderte weisse Blutkőrperchen. Flüssigkeit ziemlich stark gefürbt, enthält zablreiche Vibrionen.
$\mathrm{NaCl} \frac{1}{2} \mathrm{pCt}$.

Weisse und kernhaltige Körperchen sind nicht mebr zu finden. Serum gefärbt, mit zahlreichen Vibrionen und Zoogloea.

Hier wurden wegen der massenhaft auftretenden Vibrionen die Versuche abgebrochen.

Was nun die Deutung dieser Erscheinungen betrifit, so ist soviel klar, dass eine Auflösung fertiger rother Bluthörperchen stattfindet. In Beziehung der Umwandlung weisser Blutkörperchen in rothe wäre es aber sehr gewagt, mehr als eine Vermuthung zu äussern. Die bis zuletzt noch vorhandenen unveränderten weissen Körperehen wären dann ais gleich anfangs abgestorbene zu betrachten. Unbegreiflich bleibt nur die enorme Zahl dieser Umwandlungsproducte oder besser Uebergangsformen, die obne Theilungsprozesse der weissen Blutkörperchen gar nicht zu denken ist, wovon ich aber nie das Geringste wahrnebmen konnte. Auch an Einwanderung ist nicht zu denken, da 1) ganz dieselben Vorgänge auch ausserhalb des Körpers stattfinden und 2) nie in den Wänden der vorderen und hinteren Kammer eine entsprechende Ansammlung von Wanderzellen zu sehen war. Wenn vicht die Reihenfolge der Erscheinungen eine umgekehrte wäre, wäre immerhin sogar die Möglichkeit einer. Umwandlung rother Blutkörperchen in Betracht zu ziehen. Ich muss offen gestehen, dass es mir nicht gelungen ist, eine befriedigende Erklärung für diese Erscheinungen $z u$ finden und ich mich desbalb begnüge, die Thatsache einfach zu registriren, ohne für die angegebenen Vermuthungen einstehen $\mathrm{zu}$ wollen. Allerdings war der Anblick so frappant, dass der Gedanke der Umwandlung weisser Blutkörperchen in rothe sich beim ersten Hineinsehen in's Mikroskop sofort aufdrängte. Noch muss ich erwähnen, dass ich bei Danthon (l. c. S. 48) ein Citat aus Bowman über die Veränderung der rothen Blutkörperchen in Kammerwasser gefunden habe. Es heisst dort: D'après Bowman, les globules rouges se gonflent dans l'bumeur aqueuse, et abandonnent leur matière colorante, comme ils le feraient dans l'eau: de là leur prompte disparition. Leider konnte ich die Stelle bei Bowman selbst nicht fuden, da an der eitirten Stelle weder von Bowman, noch von rothen Blutkörperchen in 
Kammerwasser die Rede war. Mit meinen Beobachtungen steht die Stelle in directem Widerspruch, und es ist mir deshalb doppelt unangenehm, nicht den Originaltext gefunden zu haben, da ich auf ein falsches, jedenfalis auch unvollkommenes Citat keine weitere Rïcksicht nehmen kann.

Bei Injectionen von nicht defibrinirtem Blut verhält sich die Sache etwas anders. Die frei im Kammerwasser schwimmenden Blutkörperchen zeigen dieselben Veränderungen, wie beim defibrinirten Blut. Am 4. Tage sind nur noch entschieden verkleinerte, oft sternförmige rothe Blutkörperchen neben der Gerinnsel vorhanden; weisse konnte ich nicht melr entdecken. Das Gerinnsel war roth, sehr derb, körnig und enthielt keine Blutkörperchen mehr. Einmal sah ich am 2. Tage einen grauen Hof um das rothe Gerinnsel, der aber am nächsten Tage nicht mehr zu sehen war. Wahrscheinlich handelte es sich dabei um eine Fibrinausscheidung aus dem Kammerwasser auf das schon vorhandene Gerinnsel, das sich am folgenden Tage contrahirt und mit Blutfarbstoff imbibirt hatte, so dass es nicht mehr als etwas Besonderes wahrzunehmen war. Doch könnte man auch an eine Auswanderung weisser Blutkörperchen aus dem Gerinnsel denken. Da ich aber nur einmal diese Beobachtung machte und hierbei die mikroskopische Untersuchung versäumt habe, so kann ich mit Bestimmtheit weder das eirse, noch das andere behaupten.

Um zum Schlusse noch einmal die Resorption des Blutes, wie sie sich aus der vorangegangenen Darstellung ergiebt, kurz.zllsammen zu fassen, so baben wir folgende Resultate. Die löslichen Salze diffundiren einfach und werden wohl zum Theil ihren Weg anch durch die innersten Hornhautschichten nehmen. Es ist die Intercelluiarsubstanz, in der sie hauptsächlich resorbirt und weiter geschafft werden; die Zellen verhalten sich dabei mebr oder weniger passiv. Die freischwimmenden Blutkörperchen zeigen die oben beschriebenen räthselhaften Erscheinungen und lösen sich allmählich vollständig auf. Die im Gerinnsel eingeschlossenen werden durch dessen Contraction mechanisch ausgepresst und sind sebr bald nicht mehr nachzuweisen. Das Fibringerinnsel wird nur sehr allmählich gelöst, und sind die chemischen Vorgänge dabei nicht weiter bekannt. Am ungewissesten ist das Verhalten der gelösten, nicht diffusionsfihigen Stoffe, Ob sie als solche nur eben viel langsamer resorbirt 
werden, oder ob sie vorher in diffusionsfähige zerfallen müssen, konnte bis jetzt nicht nachgewiesen werden, da von Stärke der Schluss auf Hämoglobin etc. nicht erlaubt ist. Jedenfalls ist sicher, dass bei Einführung von fremden Stoffen in die vordere Kammer Fermente auftreten, die sonst im Kammerwasser nicht vorhanden sind. Stärke wird hierdurch rasch in Zucker und weitere Producte zerlegt. Ob auch Fibrin fermentativ angegriffen wird ist nicht sicher, wenn auch nicht unwahrscheinlich; jedenfalls geschieht der Zerfall des Fibrins sehr langsam. Aus der Thatsache, dass bei Injection von Stärke in's Hornhautgewebe anch die Zellen sich imbibiren, sich sogar noch dunkler färben als die Grundsubstanz, könnte man vermuthen, dass die Umwandlung der Stärke in Zucker innerbalb der Zellen geschehe; doch wäre dies noch zu beweisen. Am wahrscheinlichsten ist es, dass auch nicht diffundible Stoffe als solche resorbirt werden können, nur geht dies entsprechend langsam vor sich; denn Stärke, so gut wie Blutlaugensalz imbibirt die Corneasubstanz, wie in beiden Fällen die diffuse Blaufärbung durch das entsprecbende Reagens zeigt. Jedenfalls behalte ich mir in dieser Hinsicht noch weitere Untersuchungen vor, da die vordere Kammer fïr die Lösung dieser auch allgemein interessanten Fragen ein äusserst günstiges Feld bietet. Kann man doch mit einem kleinen Hoffman n'schen Taschenspectroskop die Absorptionslinien des Blutergusses in der Kammer direct erkennen und deren verschiedenes Verhalten unter verschiedenen Bedingungen untersuchen. 